\title{
A Novel Electrochemical Sensor Based on SH- $\beta$-cyclodextrin Functionalized Gold Nanoparticles/Reduced-Graphene Oxide Nanohybrids for Ultrasensitive Electrochemical Sensing of Acetaminophen and Ofloxacin
}

\author{
Zhiming Jiang, Guangyu Li, Mingxiao Zhang*
}

School of Chemistry and Chemical Engineering, Southwest University, Chong Qing 400715, PR China *E-mail: pclab@swu.edu.cn

doi: $10.20964 / 2017.06 .28$

Received: 2 July 2016 / Accepted: 5 September 2016 / Published: 12 May 2017

\begin{abstract}
A novel electrochemical sensor based on SH- $\beta$-cyclodextrin functionalized gold nanoparticles/reduced-graphene oxide (SH- $\beta-\mathrm{CD} / \mathrm{AuNP} / \mathrm{rGO})$ nanohybrids for ultrasensitive electrochemical sensing of acetaminophen and ofloxacin was developed. A SH- $\beta$-CD/AuNPs/rGO nanohybrids modified glassy carbon electrode (GCE) was successfully fabricated by one-pot electrochemical synthesis. The morphology and structure of the SH- $\beta$-CD/AuNPs/rGO/GCE were investigated by scanning electron microscopy (SEM) and fourier transform infrared (FT-IR). The conditions for the SH- $\beta$-CD/AuNPs/rGO/GCE preparation and the determination of acetaminophen and ofloxacin were discussed in detail. Under the optimized conditions, the differential pulse voltammograms (DPV) exhibited that the oxidation peak currents were linearly proportional to their concentrations in the range of $0.05-100 \mu \mathrm{M}$ for acetaminophen and $0.01-10 \mu \mathrm{M}$ for ofloxacin with high sensitivities of $0.26 \mu \mathrm{A} \mu \mathrm{M}^{-1}$ for acetaminophen and $0.28 \mu \mathrm{A} \mu \mathrm{M}^{-1}$ for ofloxacin, respectively. The detection limits of acetaminophen and ofloxacin were $0.03 \mu \mathrm{M}$ and $0.008 \mu \mathrm{M}(S / N=3)$, respectively. This sensor was successfully used to detect the concentrations of acetaminophen and ofloxacin in pharmaceutical formulations and human urine samples. The results suggest that the SH- $\beta$ $\mathrm{CD} / \mathrm{AuNPs} / \mathrm{rGO}$ nanohybrids has a potential application for electroanalytical sensor.
\end{abstract}

Keywords: Electrochemical sensor; $\mathrm{SH}-\beta$-cyclodextrin; gold nanoparticles; reduced-graphene oxide; acetaminophen; ofloxacin

\section{FULL TEXT}

(C) 2017 The Authors. Published by ESG (www.electrochemsci.org). This article is an open access article distributed under the terms and conditions of the Creative Commons Attribution license (http://creativecommons.org/licenses/by/4.0/). 